\title{
CO-FIRING OF LOW RANK COAL AND BIOMASS: A CHANCE FOR BIOMASS PENETRATION IN THE RENEWABLES
}

\author{
Antonio Valero \\ and the Biomass group of CIRCE composed by: \\ P. Canalís, J. Palacio, J. Pascual, J. Royo, F. Sebastián, R. Tapia. \\ CIRCE - Center of Research for Power Plant Efficiency \\ María de Luna 3, 50015 Zaragoza, SPAIN
}

\begin{abstract}
This paper presents a co-firing experience, with coal and biomass, whose objective was to prove the technical, environmental and economical feasibility (although the paper does not deal with this last one) of the implantation of this technology in a power plant of pulverised low rank coal.

Precisely, this kind of coal particularities, specially its low energy density $\left(\mathrm{kJ} / \mathrm{m}^{3}\right)$, with similar values to most of the different dry biomass resources, is what makes a difference between this project and other co-firing experiences carried out previously.

With regard to the main results, it must be pointed out that when introducing in the boiler a $5 \%$ of biomass:

- No operation problem arose and no noticeable reduction in the boiler efficiency was caused.

- Apart from the expected reductions in $\mathrm{CO}_{2}$ and $\mathrm{SO}_{2}$, an important decrease in NOx emissions was detected.

- No emissions increase of $\mathrm{CO}$, particles and volatile compounds were detected. Another aspect dealt in the project was the study of the possible impacts of forest biomass harvesting on the sustainability of the forest.

Considering the low additional investments needed for establishing a Co-firing Biomass Power Plant, this technology is a real chance for introducing biomass in Spain. It only needs the same government incentives as other renewable technologies already receive.
\end{abstract}

Keywords co-firing, low rank coal, biomass, pulverised coal

\section{INTRODUCTION}

The energy application of agricultural and forest residues generated in a territory can solve the environmental problems that their elimination means. An interesting and promising alternative is the thermo-chemical transformation of the biomass in conventional coal power plants in operation, usually referred to as co-firing. This recently developed technology consists of the substitution of a percentage of the fossil fuel (normally coal) by biomass. 
Co-firing, when compared to an exclusive use of fossil fuels for which the power plant was designed, presents important advantages, mainly socioeconomic and environmental ones, standing out the $\mathrm{CO}_{2}$ and $\mathrm{SO}_{2}$ emissions reduction. This technology, if compared to systems designed for the exclusive transformation of biomass, presents the following advantages:

- An important decrease in specific investment (per power installed unit), as it is made use of great part of the power plant facilities.

- Power generation with a higher efficiency: The characteristics of these residues (mainly its geographic dispersion and the seasonality of production) imply to work in plants of small size plants $(\leq 25 \mathrm{Mwe})$, which means low efficiency $(18-20 \%)$. The thermo-chemical transformation of biomass by co-firing obtains a much higher efficiency, the own one of great power plants $(32-36 \%)$.

- Operation flexibility: Co-firing makes feasible the easy adaptation of the power station to the availability of biomass at any time, which allows profiting advantage of seasonal resources with no need to disturb the production or to jeopardise the sustainability of its operation.

Although co-firing can be carried out in all kind of power plants, the application of co-firing technology should focus in pulverised coal units as they are the most widespread type of boilers at present.

In this type of power plants, a finely pulverised coal with low moisture is introduced into the boiler in order to obtain high generation efficiency. Due to these fuel characteristics residence time of the fuel in these boilers are very short.

As residual biomass presents different characteristics compared to fossil fuel which going to be replaced, some measures are to be taken to assure its complete combustion in a boiler that, at first, was not designed for it. Some consist of the adjustment of the fuel parameters (granulometry and moisture), and others, of the assembling in the boiler of additional feeding systems adapted to achieve the correct combustion of the residues. The suitability of the fuel compel to some requirements, mainly about granulometry and humidity, rather similar although less restrictive than those of the fossil fuel, and for that reason, biomass have the need of some pretreatments. These are, basically, drying and milling. On the other hand, the modification of the boiler for the feeding of the new fuel may involve the necessity to add specific burners, which can avoid some pretreatments but, sometimes, implies high costs and complicated modifications.

Although this is a relatively new technology, co-firing has been studied in a lot of research and pilot experiences [1], [2], [3]. However, it is necessary to prove the technical, environmental an economic feasibility in every particular case [1]. 
The type of coal used in some Spanish pulverised coal power plants offers an advantage to the thermoelectric plants that have previously tested co-firing in other countries, in which the used coals usually are quite dense and of great heating value, reason why its energy density (heating value by volume unit) is high. On the contrary, forest residues have a lower density, as well as a lesser heating value and consequently their energy density is significantly smaller. Because of this, to introduce the same amount of energy to the boiler, it is necessary to process a larger volume of fuel during the co-firing. Since the existing systems in the power plants are designed to process a certain volume by time unit, this means the necessity to count on special feeding systems and burners for the new fuel.

Nevertheless, the coal used in many Spanish power stations has an energy density quite similar to agricultural and forest residues one (see Table 1). This likeness involves a considerable reduction in investment costs needed to adapt a power plant to co-firing operation, since, the processed volume increase is practically negligible, some of the systems designed for the coal, like the burners, can be used for the residual biomass.

Table 1. Fuels characteristics.

\begin{tabular}{|l|c|c|c|}
\hline & LHV $(\mathbf{M J} / \mathrm{kg})$ & Density $\left(\mathrm{kg} / \mathbf{m}^{\mathbf{3}}\right)$ & Energy density $\left(\mathbf{M J} / \mathbf{m}^{\mathbf{3}}\right)$ \\
\hline \hline High rank coal & $26.0 \mathrm{MJ} / \mathrm{kg}$. & $1,500 \mathrm{~kg} / \mathrm{m}^{3}$ & $39,000 \mathrm{MJ} / \mathrm{m}^{3}$ \\
\hline Low rank coal & $16.3 \mathrm{MJ} / \mathrm{kg}$. & $1,000 \mathrm{~kg} / \mathrm{m}^{3}$ & $16,300 \mathrm{MJ} / \mathrm{m}^{3}$ \\
\hline Forest biomass & $17.2 \mathrm{MJ} / \mathrm{kg}$. & $700 \mathrm{~kg} / \mathrm{m}^{3}$ & $12,040 \mathrm{MJ} / \mathrm{m}^{3}$ \\
\hline Olive tree & $19.0 \mathrm{MJ} / \mathrm{kg}$ & $1000 \mathrm{~kg} / \mathrm{m}^{3}$ & $19,000 \mathrm{MJ} / \mathrm{m}^{3}$ \\
\hline
\end{tabular}

During the last two years, CIRCE Foundation has carried out the project "Co-firing in the Escucha Power Plant", reference 2fd97-0764, co-financed by the Spanish Ministry of Science and Technology and the European Union (FEDER). The project has meant the accomplishment in Spain of the first experience of operation of this technology in a pulverised coal plant.

The purpose of this project was to analyse and demonstrate the environmental, technical and economic feasibility of biomass co-firing at pulverized low rank coal power stations. Demonstration tests were conducted at a 160 MWe pulverised power plant located in Teruel province (Spain), the Escucha Power Plant.

The next sections describe some of the activities which have been developed and the results that were obtained:

- Assessment of the forest biomass resources and potential impacts on soil fertility caused by biomass harvesting.

- Modifications and new facilities at the Escucha Power Plant for the co-firing tests. 
- Real combustion tests.

- Technical and economic study of co-firing implantation.

\section{POTENTIAL IMPACTS ON SOIL FERTILITY CAUSED BY BIOMASS HARVESTING}

The harvesting of all aerial biomass, known as whole-tree harvesting (WTH), is carried out for several reasons, ranging from reduction in logging costs to provision of additional biomass for fuel, or fibre as well as ease of planting when establishing the new crop.

The harvesting of the branches, twigs and leaves together with the boles means an additional extraction of nutrients [4] which could lead to losses of productivity in the long term caused mainly by a decrease in organic matter in the soil, loss of soil nutrients and increasing acidification [5].Some studies have been carried out to asses the impact of whole-tree harvesting versus conventional harvesting, showing unlike conclusions. The complexity of nutrient cycles, the diversity of sites and the species differences, amongst other factors, stress the need for empirical evidence of possible effects of WTH in thinnings in the particular conditions of the area where the biomass will be removed from.

To asses the effect of WTH compared to conventional harvesting $(\mathrm{CH})$, the properties of the soil in a forest area near Teruel. In each plot different soil layers were sampled: litter (L), fermentation and humus layer (FH) and the 10 first centimetres of the mineral horizon (M). The plots studied are shown in the next table (Table 2).

Table 2. Number of repetitions per plot, year and treatment.

\begin{tabular}{|c|c|c|c|c|c|c|c|c|}
\hline \multirow{2}{*}{$\begin{array}{c}\text { Treatment } \\
\text { Year }\end{array}$} & \multicolumn{3}{|c|}{ Conventional Harvesting } & \multicolumn{4}{|c|}{ Whole-tree Harvesting } & \multirow{2}{*}{ No Treatment } \\
\hline & $95-96$ & $97-98$ & $99-00$ & $95-96$ & $97-98$ & $99-00$ & $77-78$ & \\
\hline Plot & $5 \mathrm{CH}$ & $7 \mathrm{CH}$ & $9 \mathrm{CH}$ & $5 \mathrm{WT}$ & $7 \mathrm{WT}$ & $9 \mathrm{WT}$ & AWT & $\mathrm{CP}$ \\
\hline Repetitions & 3 & 3 & 3 & 3 & 3 & 3 & 3 & 4 \\
\hline
\end{tabular}

$\mathrm{N}, \mathrm{P}, \mathrm{K}$, organic matter and $\mathrm{pH}\left(\mathrm{H}_{2} \mathrm{O}\right)$ were determined for the organic and mineral horizons, as well as the dry weight in the organic ones $(\mathrm{t} / \mathrm{ha})$.

The study focused on the organic matter, fertility and acidity of the soil.

Organic matter: The great differences in the amounts of organic matter in the horizons $\mathrm{L}$ and $\mathrm{FH}$ between $\mathrm{WTH}$ and $\mathrm{CH}$ get to a maximum in the plots more recently thinned, decreasing strongly these differences as the 
years since the thinning pass. In the amount $(\mathrm{t} / \mathrm{ha})$ of organic matter in horizon FH decreases lineally (

Figure 1) close to the tendency line of WTH (this tendency line goes from the values obtained in the plots 5WT to the ones in AWT). Should this tendency carry on, in less than 6-8 years after the thinning there would be no significant differences relative to organic matter between these two horizons. The differences in the $\mathrm{L}$ and $\mathrm{FH}$ horizons do not affect negatively the horizon $\mathrm{M}$, where all the plots present a higher percentage of organic matter than the control plots and there are no significant differences between $\mathrm{CH}$ and WT treatments.

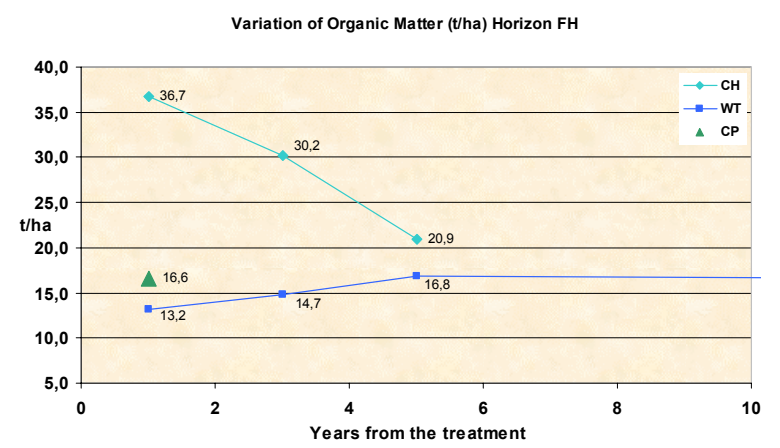

Figure 1. Variation of the amount of organic matter in horizon FH.

Fertility: The different nutrients (N, P and $\mathrm{K}$ ) studied showed a large difference in the amount of nutrients between WT and $\mathrm{CH}$ plots in recent thinnings in the organic layers, diminishing considerably this difference as they move away in time and a no significant treatment effect and a bigger percentage of nutrients in WT and $\mathrm{CH}$ plots than in control plots in horizon $\mathrm{M}$ )

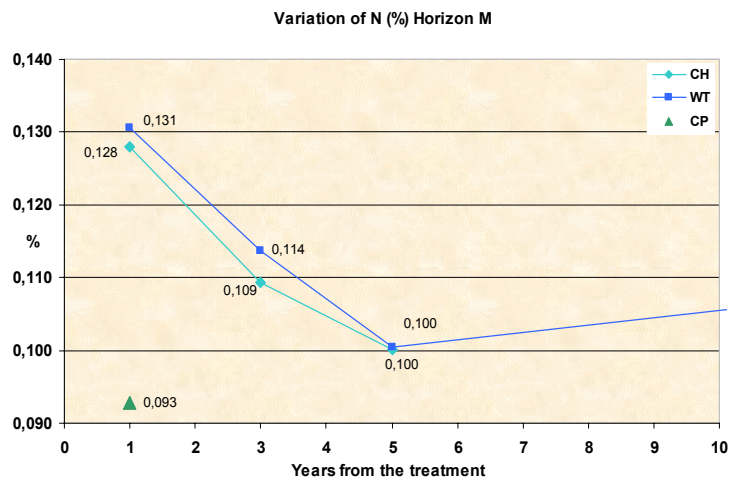

Figure 2. Variation of $N(\%)$ in horizon $M$. 
Acidity: $\mathrm{pH}$ increases in WT plots during the first years after the thinning (Figure 3), but three or four years after, the $\mathrm{pH}$ is lower in the $\mathrm{CH}$ plots than in the WT. Unlike to Nykvist and Rosen (1985) [6] who found a $\mathrm{pH}$ reduction when the slash was removed from the site 1-10 years after the harvesting, the acidity increase following WT has turned into a decrease 4 years after the thinnings. In all the horizons, $\mathrm{pH}$ after WT is higher than $\mathrm{pH}$ in control plots.

Despite the fact that whole-tree harvesting removes greater quantities of nutrients from the site than conventional harvesting, the results show that whole-tree harvesting could be practised when thinning Pinus nigra and $P$. sylvestris without short and middle term impacts on the soil properties most easily affected by WTH. However, it is premature to draw any definite conclusion on long-term environmental viability of WTH, being required further research to totally guarantee the harmlessness and sustainability of this practice.

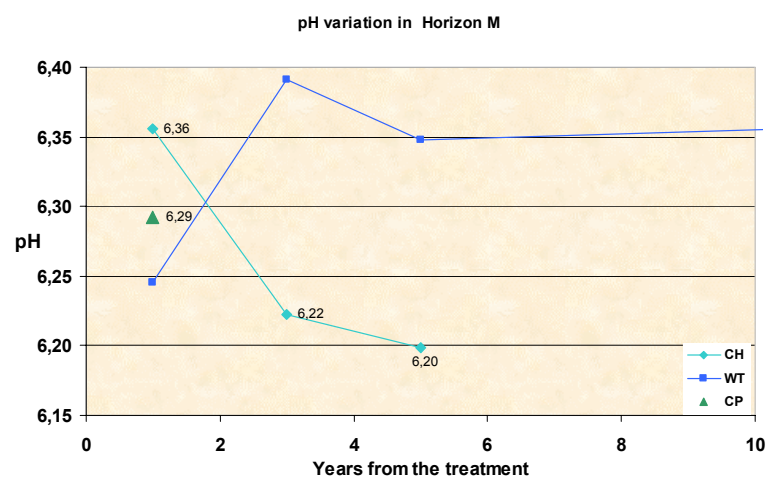

Figure 3. pH variation in horizon $M$.

\section{MODIFICATIONS AND NEW FACILITIES AT THE ESCUCHA POWER PLANT FOR THE CO-FIRING TESTS}

One of the most important goals of this project was to carry out demonstration tests in real power plant operation conditions. To ensure complete combustion of biomass in a pulverised coal utility boiler it is necessary to adapt particle characteristics, for this reason a pilot pretreatment plant was designed as well as the more convenient handling and feeding equipment was defined considering technical and economic aspects.

The pre-treatment plant was designed to be capable of achieving different particle sizes and moisture contents in order to determine the 
influence of those parameters in co-firing efficiency. It was made up of a rotary drier, a hammer mill with a previous knife ring stage, a sieve which allowed size classification and a silo where biomass was stored up until it was used in a test.

It was also necessary to define the way to inject biomass in the boiler. In some cases existing coal burners are removed and replaced with a specially designed biomass burner and in other cases separate biomass burners are added, usually at the bottom part of the boiler [2], [7]. The introduction of biomass into the boiler through existing coal burners is not frequent due to the different properties of both fuels, nevertheless the coal used at the Escucha Power Plant has similar energy density to the one of the forest biomass and for this reason biomass was handled separately from the coal and injected into the boiler independently through a central duct existing in the coal burners.

The boiler has sixteen burners placed in four floors (four by each). In burners located at first and third floors this central duct is utilized to lodge a diesel oil lance used for the startings, whereas in burners located at the second and fourth floor they are used to introduce certain amount of secondary air reason why in these floors it was possible to use them to inject biomass in the center of the coal flame.

Previous experiences agreed that it is more advisable to inject biomass at the bottom part of the boiler because residence time of biomass particles is increased and therefore risks of unburned carbon in fly and bottom ashes is reduced [8]. For that reason it was decided to use the second row of burners.

The characteristics and dimensions of existing burners were analysed and results showed that in order to introduce up to 5\% biomass on an energy basis it would be enough with using the central duct of a single burner. Despite, in order to obtain a symmetric fuel distribution into the boiler it was decided to inject biomass particles through both central burners instead of doing it only through one of them. Figure 4 shows burners layout in the boiler and the two of them which were used to inject biomass.

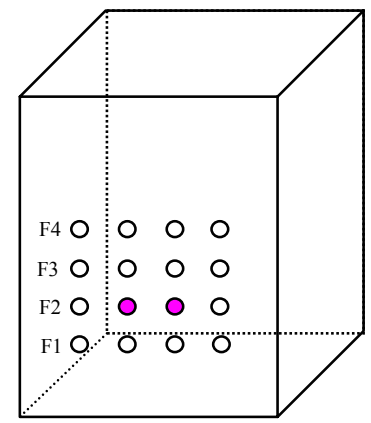

Figure 4. Boiler scheme. Localization of the two burners used to inject biomass. 
From the silo, biomass was transported pneumatically (primary air) to the boiler by means of a fan $\left(5,300 \mathrm{~m}^{3} / \mathrm{h}, 700 \mathrm{mmH}_{2} \mathrm{O}\right.$ and $\left.30 \mathrm{HP}\right)$ and pipelines installed from the rotary feeder to the burners. The rest of the air needed to achieve complete combustion of biomass particles was obtained from existing coal secondary air ducts. Figure 5 shows both fuel feeding systems.

In order to avoid biomass feeding problems existing burners were lightly modified. The most important aspects that were considered in the realization of these modifications were:

- Certain quantity of secondary air introduction into biomass ducts. To prevent self-ignition risks biomass primary air had ambient temperature. In order to avoid boiler efficiency reduction a certain quantity of coal secondary air $\left(\approx 300^{\circ} \mathrm{C}\right)$ was introduced near biomass particles entrance to the burner to increase biomass and its primary air temperature to one similar to coal entrance $\left(\approx 75^{\circ} \mathrm{C}\right)$.

- In order to improve flame formation and stability, biomass and air fluid dynamics in the burner outlet was taken into account. With these considerations the final component of the central duct was modified preventing duct blockages and ensuring that biomass particles were launched into the central part of the coal flame avoiding unburned carbon.

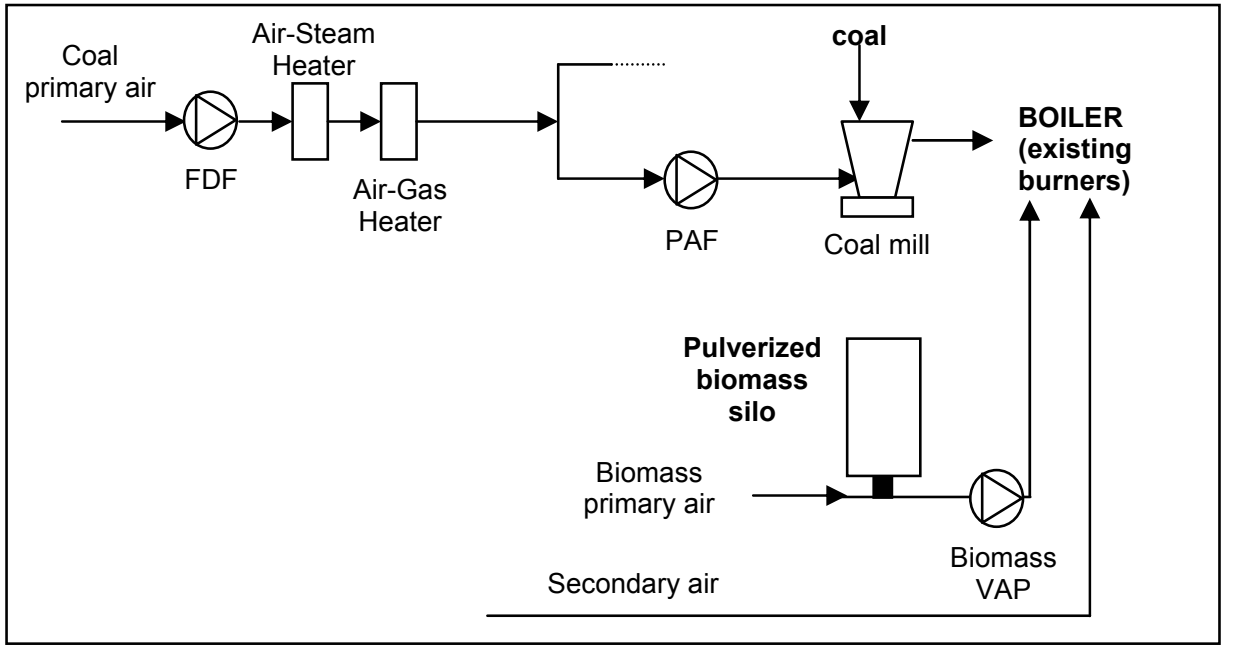

Figure 5 Fuels feeding systems scheme. 


\section{REAL COMBUSTION TESTS}

\section{Planning of the tests}

A set of tests in real operation conditions was carried out to prove the technical viability of co-firing in this type of power plant. The biomass used in the tests was forest biomass (Pinus sylvestris y Pinus nigra) harvested in thinnings in stands close to the power plant. The amount of biomass introduced meant, approximately, a $5 \%$ of the load (up to $8 \mathrm{MWe}$ ) as, apart from being a technically suitable value, did not jeopardise biomass resources in the area (anticipating a possible future were this technology could be used in a continuous way).

Test objectives were:

- To study biomass and coal combustion process in the power plant, comparing it with the exclusive coal combustion.

- To assess likely variations in boiler efficiency caused by the introduction of biomass with different particle size and moisture content.

- To determine the characteristics that should accomplish the biomass to achieve a satisfactory combustion in a power plant designed originally to burn low rank coal.

- To check the reduction in pollutant emissions obtained by co-firing compared to an exclusive use of low rank coal.

- To evaluate the possible problems arisen, caused by co-firing, during the operation of the power station in real conditions.

Every co-firing test was carried out trying to not disturb usual plant operation and for this reason sootblowing sequences and operating manoeuvres were always respected.

A total of 15 tests were done in which effect of fuel moisture and particle size on flame stability and burnout was analysed. Biomass particle size was modified between $1.26 \mathrm{~mm}$ and $5 \mathrm{~mm}^{1}$ and moisture content between $3 \%$ and $15 \%$ on dry basis. Although it was anticipated that every test was going to be at full load an important failure in one of the two induced draft fans forced that the last six tests were realized at medium load.

The Escucha Power Plant has four coal mills but some of the co-firing tests were done with only three of them working. This affects coal flame position into the boiler and implies the necessity to work with different boiler air distribution.

\footnotetext{
${ }^{1} 100 \%$ of the particles passed through those sieve fractions.
} 
Moreover, co-firing tests were carried out at different ambient temperatures (which in the Escucha Power Plant implies important variations in the steam flow rate generated and its pressure because the condenser is refrigerated with ambient air) and with different quality coals.

\section{Tests results}

Co-firing influence on load, efficiency and boiler working parameters.

In none of all the boiler operation ways analysed in the tests, the replacement of a $5 \%$ of coal by biomass caused the slightest operation problem in the power plant. During the tests, the load in co-firing always reached to the anticipated values, without any additional problem due to the fuel nature.

Boiler efficiency was only affected, in a minor way, and for the tested particle size, it observed that:

- Unburned coal (fixed carbon) in fly ashes experienced minimal variations, from a $0.3 \%$ reduction to a $0.3 \%$ increase.

- Unburned coal (fixed carbon) in slag increased slightly, not more than $0.1 \%$.

At worst, these increases in unburned coal could mean an efficiency reduction of $0.01 \%$.

Burning a fuel with a very different volatile content, compared to the one for which the boiler was designed, could affect the boiler efficiency and so this effect was assessed. The efficiency could experience a decrease as the central coal flame could have shifted up inside the boiler and caused a faulty heat transfer to the tubular plate.

Irradiation charts were made for each test in different stages: before feeding the boiler with biomass, during co-firing and once the boiler was working again with just coal. Comparing those irradiation charts, it was observed that the central coal flame was more centred during co-firing as biomass was exclusively fed through the two central burners. A small rise of the central coal flame occurred although it was not enough to alter boiler heat transfer.

Emissions variations during co-firing tests:

CO: The measurement of the $\mathrm{CO}$ emissions showed that the substitution of a $5 \%$ (in power) of the coal by biomass did not involve any appreciable increase of $\mathrm{CO}$ emissions, in fact, the average of all the tests supposed a slight reduction (14 ppm with coal and $13.5 \mathrm{ppm}$ with biomass) as it is reflected in the

Figure 6. Although a part of this diminution is due to minor variations in the operation way of the power station, it should not be justified by the best behaviour of the biomass in the boiler (due to its greater oxygen content). Nevertheless, it may be concluded that the co-firing does not mean an increase in the emissions of this compound. 


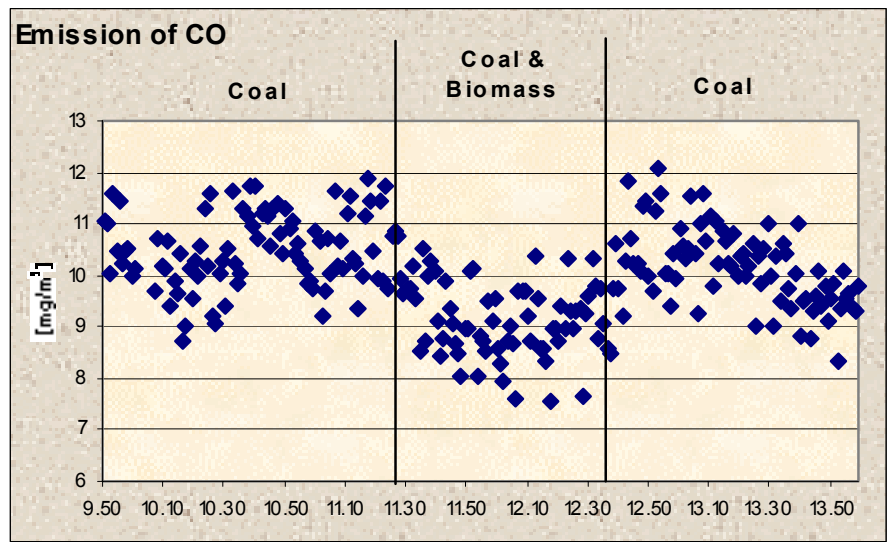

Figure 6. Variation of $\mathrm{CO}$ emissions during a test.

Volatile compounds: The determination of the variation of these emissions was carried up in an indirect way, controlling the central coal flame in the boiler. It was stated that, in spite of the ascent that it suffered, it was not so important as to suppose an increase of the volatile compound emission.

NOx: Nitrogen content of biomass is lower than coal content, which supposes to reduce the formation of NOx. Nevertheless, the formation of thermal or proximate NOx is directly related to the operation ways, which, as it has been mentioned before, varied very little. The gas analyses made in the tests have shown that when burning the biomass, NOx emissions diminished on the average more than $3 \%$, reduction that may be caused by synergetic effects, effects already pointed in previous studies [9].

Figure 7 represents the variation of NOx emissions during a test.

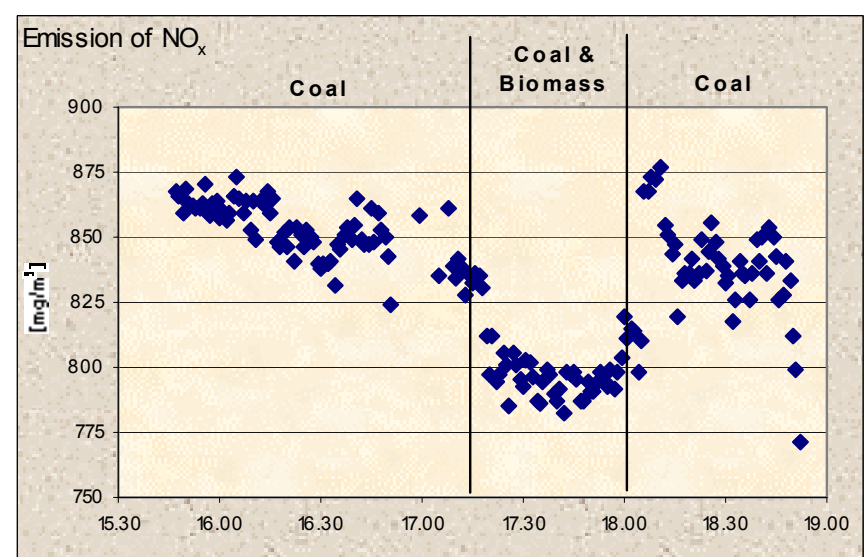

Figure 7. Variation of $N O_{x}$ during a test. 
SO2: Coal replacement by a fuel with a practically negligible sulphur content, involves a reduction in $\mathrm{SO}_{2}$ emissions, reduction verified in each test.

Partícles: A faulty combustion could have meant an increase in particle emissions, despite the lower ashes content in biomass than in coal. After analysing the data obtained during the tests, no significant differences were found. Although in some tests it is possible to appreciate a reduction in particle emissions, data dispersion let only conclude that particle emissions in co-firing tests were not different to the emissions obtained when burning exclusively coal.

Lastly, two tests were carried out with a humidity percentage close to $15 \%$ and with a particle size of $3 \mathrm{~mm}$. No differences were noticed compared to the co-firing of biomass with a low moisture percentage. This result would allow the utilisation of the new fuel without requiring a forced drying, with the consequent reduction in the investment and operation costs, improving the economic viability of co-firing.

\section{CONCLUSIONS}

After analysing the results attained in the tests carried out in Escucha Power Plant, it has been confirmed the technical and economical feasibility of co-firing of low rank coal and forest biomass (5\% approximately), introducing the biomass through the existing burners. It must be pointed out:

- Biomass may be used with a granulometry much larger (up to $5 \mathrm{~mm}$ ) than the granulometry initially considered. Even with the largest particle size, boiler efficiency was practically steady.

- In none of the operation ways tested (full load, partial load, operation with 3 and 4 coal mill) and during the test, there has been any plant operation problem at all.

- It has been confirmed the already expected reduction in $\mathrm{SO}_{2}$ and $\mathrm{CO}_{2}$ emissions. In all cases, important $\mathrm{NO}_{\mathrm{x}}$ have been measured $(3 \%$ in average). The operation parameters showing a greater reduction (up to $15 \%$ ) must be studied in a deeper way. Neither CO nor solid particle emissions have increased.

- It is feasible to introduce the biomass in the boiler without a previous forced drying (just natural drying). Nevertheless, further test should be carried out with full load.

From the previously commented, It may be concluded that co-firing of low rank coal and biomass in a pulverised coal power plant is, without deep alterations or investment, technically feasible, and economically quite profitable, provided that the government incentives given to other renewable technologies for electricity production would also be obtained. 


\section{ACKNOWLEDGEMENTS}

We want to express our deepest thankfulness to:

The Comisión Interministerial de Ciencia y Tecnología (CICYT) and The European Commission, whose financing made possible the realisation of this project.

Production and Engineering and R+D departments of Endesa Group, for believing since the first day in this project, for allowing its realisation in one of its power plants and for their collaboration in the proper carrying out of the tests.

VIESGO Direction, for allowing the project to go on ahead and carrying on supporting it.

\section{REFERENCES}

1. Bemtgen, J.M., Hein, K.R.G., Minchener, A.J. "Combined combustion of Biomass/Sewage Sludge and Coal. Volume II: Final Reports" IVD, University of Stuttgart, 1995. ISBN 3-928123-16-5

2. Spliethoff, H., Hein, K.R.G. "Co-combustión of coal and Biomass. Suitability of Combustion Systems and State of the Art". IVD, University of Stuttgart. Symposium Co-combustion and Gbiofuels, Nijmegen/NL, 8-9 November 1995.

3. Spliethoff, H., Hein, K.R.G. "Combined combustion of coal and biomass in pulverized fuel and fluidized bed systems". IVD, University of Stuttgart. $3^{\text {rd }}$ Int. Conf. On Combustion Technology, 3-6 July 1995.

4. Wright, T.W., \& Will, G.M. 1958. The nutrient content of Scots and Corsican pines growing on sand dunes. Forest Ecology 31: 13

5. Maliondo, S.M. 1988: Possible effects of intensive harvesting on continuous productivity of forest lands. FC Maritimes, Inf. Rep. M-X-171.

6. Nykvist, N. Y Rosen, K. 1985: Effects of clear-cutting and slash removalon the acidity of northern coniferous soils. Forest Ecology Management 11:157-170.

7. Järvinen T., Alakangas E., "Cofiring of biomass - evaluation of fuel procurement and handling in selected existing plants and exchange of information (COFIRING).”. VTT Energy, 2001

8. http://www.eren.doe.gov/biopower/bplib/library/biomasscofire.pdf

9. Robinson, A., Baxter, L., Junker, H., Shaddix, C., Freeman, M., James, R., Dayton, D. "Fireside issuies associated with coal-biomass co-firing". National Renewable Energy Laboratory (NREL), Sandia National Laboratories, Federal Energy Technology Center. NREL/TP-570-25767, December 1998 